Check for updates

Cite this: RSC Adv., 2019, 9, 26464

Received 20th June 2019

Accepted 1st August 2019

DOI: $10.1039 / c 9 r a 04638 k$

rsc.li/rsc-advances

\section{Experimental and theoretical research on a new corrosion inhibitor for effective oil and gas acidification}

\author{
Yongming Li, ${ }^{a}$ Dingli Wang (D) *a and Lei Zhang ${ }^{\text {b }}$ \\ A new dibenzylamine-quinoline derivative (DEEQ) was synthesized and investigated as a corrosion inhibitor \\ for mild steel in $15 \% \mathrm{HCl}$ solution in various ways, including via weight loss measurements, contact angle \\ measurements, electrochemical measurements (EIS), scanning electron microscopy (SEM), scanning \\ Kelvin probe (SKP) and theoretical calculations. The experimental results revealed that DEEQ is an \\ effective corrosion inhibitor for oil and gas acidification. In an oil-water two-phase system, the \\ wettability of mild steel can be changed by adsorption, while obeying the Langmuir adsorption isotherm. \\ Finally, quantum chemical calculations and molecular dynamic simulation parameters further show \\ a definite correlation between the theoretical and experimental results.
}

\section{Introduction}

Metal acid corrosion not only wastes precious resources and energy but also seriously pollutes the environment. Under the action of corrosion, $10 \%$ of the world's steel output is corroded and consumed each year, especially in the corrosion and rust cleaning of mechanical equipment, pipelines of natural gas and long-distance transmission systems. ${ }^{13}$ A hydrochloric acid solution not only corrodes equipment, but the acid mist also causes harm to people. Therefore, adding a corrosion inhibitor is an economical and effective method that has received increasing attention. . $^{6,38}$

According to the chemical composition, a corrosion inhibitor is divided into two parts: an inorganic portion and an organic inhibitor. The organic inhibitor molecules contain a highly electronegative polar group $(\mathrm{O}, \mathrm{N}, \mathrm{S}$, etc. $)$, benzene ring, heteroatom ring, double bond or triple bond, and are mostly used in an acidic corrosion medium. ${ }^{4}$ The unpaired lone pair of electrons or the high electron cloud density region of the bond coordinates with the metal orbital in the form of a coordination bond, and forms a protective film by interface transformation, polymerization and chelation., ${ }^{3,5,35}$

Most literature reports the use of a Mannich base as a corrosion inhibitor for effective oil and gas acidification., ${ }^{\mathbf{9} 6,37,41}$ Although Mannich bases have a good inhibition effect, there are still many problems that limit their application such as high cost, toxicity and instability. With the enhancement of people's awareness of environmental protection, research on green

${ }^{a}$ State Key Laboratory of Oil and Gas Reservoir Geology and Exploitation, Southwest Petroleum University, Chengdu 610500, Sichuan, China. E-mail: wdl_swpu@163.com ${ }^{b}$ College of Chemistry and Chemical Engineering, Chongqing University, Chongqing 400044, China corrosion inhibitors represented by quaternary ammonium salt ionic liquids has received more and more attention. At the same time, the hydrophobic chains can align on the metal surface to form a hydrophobic film, which hinders the diffusion of water molecules into the cathode region and inhibits the cathode reaction. ${ }^{17,18}$ In addition, because of the molecular structure itself, the cations and anions can form a wide range of structures..$^{\mathbf{8 1 1 , 1 2 , 2 0}}$ In previous literature, imidazolium-based and benzimidazole ionic liquids were researched as inhibitors for mild steel in acid solution, and the results provide guidance or direction to design and develop new ionic liquids as inhibitors. In particular, the long alkyl chain induced poor water solubility and foaming ability are detrimental for corrosion inhibitors. Thus, short chain and special functional groups became the direction for design. A dibenzylamine-quinoline derivative has not been reported as a corrosion inhibitor, and the properties of good water solubility and stability and the functional groups determine its excellent corrosion inhibition performance. Therefore, in this paper, we synthesized a new corrosion inhibitor, and the mechanism of corrosion between the inhibitor molecule and the mild steel surface was studied. The test methods include weight loss, potentiodynamic polarization, electrochemical impedance spectroscopy (EIS), scanning Kelvin probe (SKP), and scanning electron microscopy (SEM). In addition, the corrosion mechanism was researched further via theoretical quantum chemical calculations and molecular dynamic simulations.

\section{Experimental and methods}

\subsection{Preparation of samples}

The composition of the mild steel samples (wt\%) was $\mathrm{C}(0.26 \%)$, Si (0.2\%), Mn (0.49\%), P (0.009\%), S (0.004\%), Si (0.2\%) and Fe 
for balance. The specimens were tested for weight loss and surface topography analysis was carried out at a size of $50 \mathrm{~mm}$ $\times 10 \mathrm{~mm} \times 3 \mathrm{~mm}$. The mild steel specimen was cleaned ultrasonically with anhydrous ethanol and acetone. After natural drying, the mass of the specimen was accurately weighed using an analytical balance, and the measurement was performed in parallel three times. The results are expressed as average values.

The molecular structure of the inhibitor DEEQ is shown in Fig. 1, and the synthesis was as follows. Dibenzylamine (3.94 g, $20 \mathrm{mmol}$ ) was added to a $250 \mathrm{~mL}$ single-necked flask with $100 \mathrm{~mL}$ ethanol as the solvent. Epichlorohydrin (1.95 g, 21 $\mathrm{mmol}$ ) was added dropwise, and the reaction was stirred at $50{ }^{\circ} \mathrm{C}$ for $16 \mathrm{~h}$. Then rotary evaporation was carried out to remove the solvent and a yellow viscous liquid was obtained. Afterwards, the yellow viscous liquid $(2.88 \mathrm{~g}, 10 \mathrm{mmol})$ dissolved in $150 \mathrm{~mL}$ ethanol was introduced to a $250 \mathrm{~mL}$ single-necked flask, and quinoline $(1.42 \mathrm{~g}, 11 \mathrm{mmol})$ was added to the reaction system, and the system was equipped with a stirrer and a reflux condenser at $80{ }^{\circ} \mathrm{C}$ for $12 \mathrm{~h}$. Finally, rotary evaporation was carried out to remove the solvent and after washing with ethyl acetate three times, a white solid was obtained. The ${ }^{1} \mathrm{H}$ NMR measurement was carried out using a Bruker AVANCE III HD 400 NMR Spectrometer. ${ }^{1} \mathrm{H}$ NMR for DEEQ: $\delta$ (ppm): 1.1 $(1 \mathrm{H}, \mathrm{m}, \mathrm{CH}-\mathrm{OH}), 1.2\left(2 \mathrm{H}, \mathrm{m}, \mathrm{N}-\mathrm{CH}_{2}\right), 2.1\left(1 \mathrm{H}, \mathrm{m}, \mathrm{CH}_{2}-\mathrm{CH}-\right.$ $\left.\mathrm{CH}_{2}\right), 3.6-3.8\left(4 \mathrm{H}, \mathrm{m}, \mathrm{CH}_{2}-\mathrm{N}-\mathrm{CH}_{2}\right), 5.2\left(2 \mathrm{H}, \mathrm{m}, \mathrm{N}^{+}-\mathrm{CH}_{2}\right), 7.2-8.1$ (16H, m, Ar-H), $9.0\left(1 \mathrm{H}, \mathrm{m}, \mathrm{N}^{+}-\mathrm{H}\right)$.

\subsection{Contact angle measurements}

Contact angles were measured using an automatic tensiometer (GERMAN KRUSS DSA30S) at $20{ }^{\circ} \mathrm{C}$. The experiments were performed under aqueous solution, and the dynamic contact angle was measured by observing the change of contact angle with time in the presence and absence of corrosion inhibitor.

\subsection{Weight loss measurements}

Weight loss measurements are one of the most reliable methods for determining the uniform corrosion rate and the corrosion inhibitor performance of metals, which is the basis of other test methods. ${ }^{25-27}$ In the process of the experiment, three
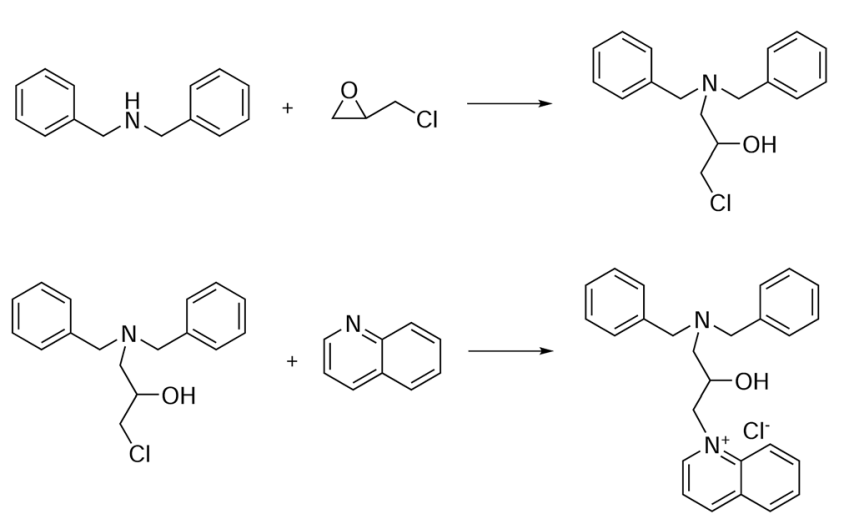

Fig. 1 Synthetic route to DEEQ. samples were suspended from each jar, and the specimens were immersed in a $15 \% \mathrm{HCl}$ solution with different concentrations of DEEQ for $4 \mathrm{~h}$ at 333, 343, 353 and $363 \mathrm{~K}$. The temperature of the solution was kept steady by the water bath, and at the end of the experiment the specimens were removed, the surface washed with water and the corrosion products removed. The specimens were then cleaned with anhydrous ethanol and acetone carefully, and after natural drying the mass of the sample was accurately weighed by an analytical balance, and measured in parallel three times, and the results are expressed as an average value. The corrosion rate was calculated.

\subsection{Electrochemical measurements}

Electrochemical tests can not only obtain instantaneous data from the metal corrosion process but can also continuously monitor the change in the metal electrode during the corrosion process. $^{2,31}$ Electrochemical experiments were carried out using the traditional three-electrode system by Reference 3000 (Gamry). A graphite electrode and a saturated calomel electrode (SCE) were used as the auxiliary and reference electrodes, respectively. ${ }^{42,43}$ In addition, a mild steel electrode was employed as the working electrode with an exposed area of 1.0 $\mathrm{cm}^{2}$. Before starting the experiments, the polished working electrode was cleaned with anhydrous ethanol and acetone and then immersed in the test solution for $20 \mathrm{~min}$ to reach a steady potential, and the measurements were performed in the frequency range of $10^{-2}$ to $10^{5} \mathrm{~Hz}$ with an amplitude of $5 \mathrm{mV}$ at open circuit potential (OCP). The EIS parameters were obtained by fitting the data to an equivalent circuit by using ZSimpWin software. The potentiodynamic polarization curves were obtained in a potential range of $-500 \mathrm{mV}$ to $500 \mathrm{mV}$ with a scan rate of $0.5 \mathrm{mV} \mathrm{s}^{-1}$.

\subsection{Scanning Kelvin probe}

Compared with traditional electrochemical impedance spectroscopy (EIS) technology, scanning Kelvin probe (SKP) technology can analyze the potential distribution on the metal surface, measure the electrochemical properties without contacting the system, and more accurately reflect the characteristics of local corrosion of the metal, which is extremely sensitive to small changes in the interface state. In addition, SKP has high measurement accuracy, and the electrochemical characteristics can be three-dimensionally presented.

The SKP experiment was carried out using a micro area electrochemical scanning system (VersaScan of Princeton Applied Research) at $298 \mathrm{~K}$, using the scan step mode with a scan step size of $100 \mu \mathrm{m}$, scan area of $4000 \times 4000 \mu \mathrm{m}^{2}$, probe vibration amplitude of $30 \mu \mathrm{m}$, scan frequency of $80 \mathrm{~Hz}$, and an average distance of the probe from the sample surface of approximately $100 \mu \mathrm{m}$. In addition, the SKP system was calibrated with a saturated calomel electrode (SCE) before testing.

\subsection{Surface analysis}

Surface morphology analysis experiments were carried out using a scanning electron microscope (SEM) (FEI Quanta 450), and the acceleration voltage was $20 \mathrm{kV}$ and the magnification 
was 150 to 1000 times. SEM can accurately reflect the surface morphology of the metal after corrosion and provides a very valuable reference for the evaluation of corrosion inhibitor performance. Before starting the experiments, the surface should be cleaned with anhydrous ethanol and acetone carefully before natural drying. In this process, the fresh specimen and the specimens immersed in $15 \% \mathrm{HCl}$ solution in the absence or presence of $6.0 \mathrm{mM}$ DEEQ for $4 \mathrm{~h}$ were examined.

\subsection{Quantum chemical calculations}

The molecular structure parameters of the corrosion inhibitor and the interaction mode and active sites between the molecules and the metal can be obtained through quantum chemical calculations, which provide important information for researching the mechanism of the corrosion inhibitor. ${ }^{19}$ In the Gaussian 09 program, the geometry of the studied molecules was optimized at the 6-31 $\mathrm{g}(\mathrm{d}, \mathrm{p})$ basis set level, and the frequency calculation was performed at the same basis level to determine that the found stagnation point was the minimum energy point. After the simulations, the energy of the highest occupied molecular orbital ( $E_{\text {HOMO }}$ ), the energy of the lowest unoccupied molecular orbital $\left(E_{\mathrm{LUMO}}\right)$, the energy gap $(\Delta E=$ $\left.E_{\mathrm{LUMO}}-E_{\text {Номо }}\right)$, the dipole moment $(\mu)$, and the Mulliken charge were calculated.

\subsection{Molecular dynamic simulations}

The Forcite module of Materials Studio was used to model the interaction between inhibitor and iron surface. The calculation model consists of two layers: the surface layer of Fe (100) and the water layer with corrosion inhibitor molecules. The adsorption interface Fe (100) crystal plane thickness is 8 layers, a total of $512 \mathrm{Fe}$ atoms, and the system size is $2.30 \mathrm{~nm} \times$ $2.30 \mathrm{~nm} \times 1.15 \mathrm{~nm}$. The solvent layer was established using the amorphous Cel I module and consists of an inhibitor molecule and 500 water molecules with a system size of $2.30 \mathrm{~nm} \times$ $2.30 \mathrm{~nm} \times 2.84 \mathrm{~nm}$. In addition, the temperature was $298.15 \mathrm{~K}$ and the integration time step was set to $1 \mathrm{fs}$. After the simulations the interaction energy $\left(E_{\text {int }}\right)$ between the inhibitor molecule and the iron surface was calculated as follows:

$$
E_{\mathrm{int}}=E_{\mathrm{tot}}-E_{\mathrm{mol}}-E_{\mathrm{sur}}
$$

where $E_{\text {tot }}$ is the total energy of the simulation system, $E_{\mathrm{mol}}$ is the energy of a free inhibitor molecule, and $E_{\text {sur }}$ is the energy of the iron surface together with the water molecules.

\section{Results and discussion}

\subsection{Contact angle measurements}

It can be seen from Fig. 2 that the wettability of steel is greatly changed in the presence of DEDB, and because the measurements were performed under aqueous conditions the supplementary angle of the results is the real contact angle. For the fresh steel, the surface contact angle is $78^{\circ}$, which is consistent with the previous reports. ${ }^{\mathbf{1 , 3 4}}$ When adding corrosion inhibitor after 1,2 and 3 hours, the contact angle of the steel is $118^{\circ}, 127^{\circ}$

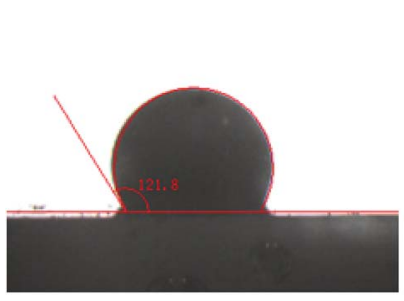

(a)

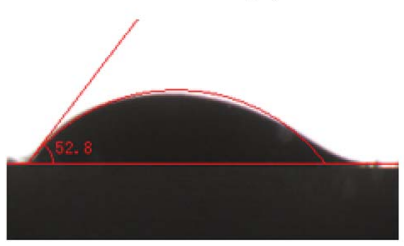

(c)

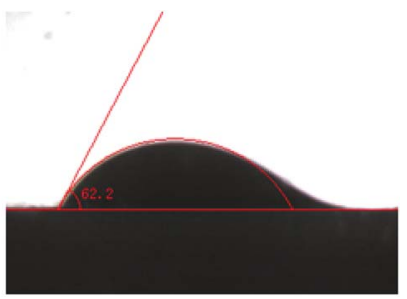

(b)

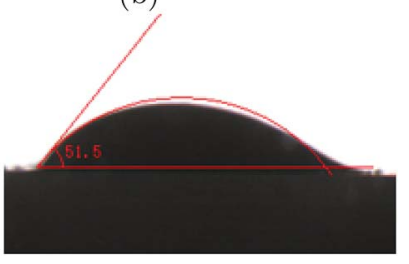

(d)
Fig. 2 The cross sectional optical images of oil droplets on (a) the fresh steel surface, (b) the steel surface inhibited with $7 \mathrm{mM} D E E Q$ after $1 \mathrm{~h}$ immersion, (c) the steel surface inhibited with $7 \mathrm{mM} \mathrm{DEEQ}$ after $2 \mathrm{~h}$ immersion, and (d) the steel surface inhibited with $7 \mathrm{mM}$ DEEQ after $3 \mathrm{~h}$ immersion.

and $128^{\circ}$, respectively, which indicates that the surface of the steel changed to lipophilic. The DEEQ molecules adsorbed on the steel surface to form the aligned adsorption layer, reducing the free energy of the interface so that water molecules can be displaced more effectively, leading to a high inhibition efficiency.

Table 1 Weight loss measurements for mild steel in $15 \% \mathrm{HCl}$ with different concentrations of DEEQ for $4 \mathrm{~h}$ at different temperatures

\begin{tabular}{|c|c|c|c|c|}
\hline $\begin{array}{l}\text { Temperature } \\
\text { (K) }\end{array}$ & $\begin{array}{l}\text { Concentration } \\
(\mathrm{mM})\end{array}$ & $v\left(\mathrm{~g} \mathrm{~m}^{-2} \mathrm{~h}^{-1}\right)$ & $\eta(\%)$ & $\theta$ \\
\hline \multirow[t]{6}{*}{333} & Blank & 18.116 & - & - \\
\hline & 1.0 & 1.410 & 92.2 & 0.922 \\
\hline & 3.0 & 0.746 & 95.9 & 0.959 \\
\hline & 4.0 & 0.411 & 97.7 & 0.977 \\
\hline & 6.0 & 0.314 & 98.3 & 0.983 \\
\hline & 7.0 & 0.179 & 99.0 & 0.990 \\
\hline \multirow[t]{6}{*}{343} & Blank & 72.464 & - & - \\
\hline & 1.0 & 6.90 & 90.5 & 0.905 \\
\hline & 3.0 & 5.391 & 92.6 & 0.926 \\
\hline & 4.0 & 3.169 & 95.6 & 0.956 \\
\hline & 6.0 & 1.948 & 97.3 & 0.973 \\
\hline & 7.0 & 1.476 & 98.0 & 0.980 \\
\hline \multirow[t]{6}{*}{353} & Blank & 271.739 & - & - \\
\hline & 1.0 & 47.582 & 82.5 & 0.825 \\
\hline & 3.0 & 30.170 & 88.9 & 0.889 \\
\hline & 4.0 & 14.875 & 94.5 & 0.945 \\
\hline & 6.0 & 9.814 & 96.4 & 0.964 \\
\hline & 7.0 & 4.790 & 98.2 & 0.982 \\
\hline \multirow[t]{6}{*}{363} & Blank & 825.525 & - & - \\
\hline & 1.0 & 148.696 & 81.9 & 0.819 \\
\hline & 3.0 & 97.198 & 88.2 & 0.882 \\
\hline & 4.0 & 87.256 & 89.4 & 0.894 \\
\hline & 6.0 & 64.198 & 92.2 & 0.922 \\
\hline & 7.0 & 37.964 & 95.4 & 0.954 \\
\hline
\end{tabular}




\subsection{Weight loss measurements}

The results of the weight loss measurements for mild steel in $15 \% \mathrm{HCl}$ with different concentrations of DEEQ for $4 \mathrm{~h}$ at different temperatures are shown in Table 1 . The experimental parameters of corrosion rate $(v)$, inhibition efficiency $(\eta)$ and surface coverage $(\theta)$ were calculated by the following equations: ${ }^{24}$

$$
\begin{aligned}
v & =\frac{w_{0}-w}{S t} \\
\eta(\%) & =\frac{v_{0}-v}{v_{0}} \times 100 \\
\theta & =\frac{v_{0}-v}{v_{0}}
\end{aligned}
$$

where $w_{0}$ and $w$ are the weight values without and with inhibitor, $S$ is the total surface area of the mild steel specimen, $t$ is the immersion time, $\theta$ is the surface coverage, and $v_{0}$ and $v$ are the corrosion rate of mild steel in the absence and presence of inhibitor, respectively. ${ }^{30}$

From Table 1, it was found that with an increase in inhibitor concentration, the corrosion rate decreases, and the inhibitor efficiency and surface coverage increases, which indicates that increasing the concentration leads to an increase in the amount of adsorption. At the same concentration, when the temperature increases the corrosion efficiency decreases. When the

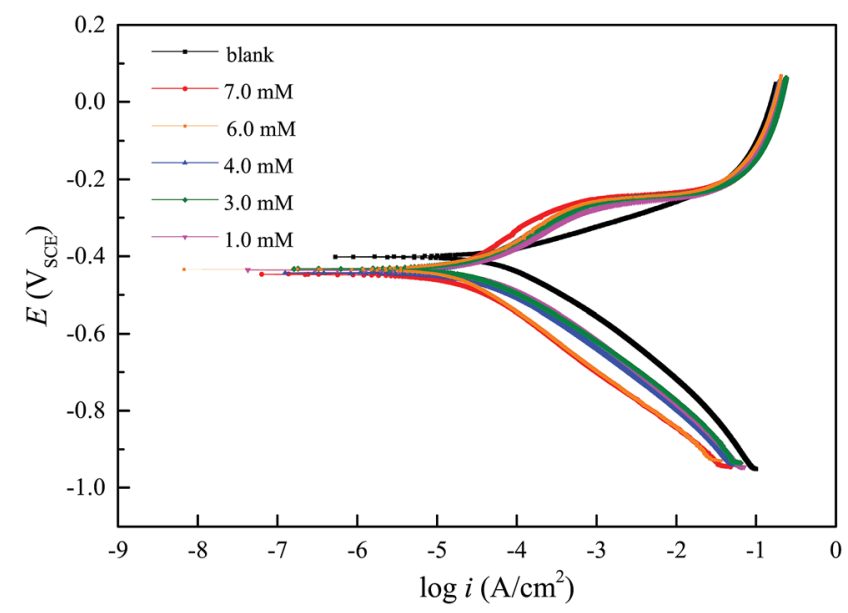

Fig. 3 Polarization curves for mild steel in $15 \% \mathrm{HCl}$ solution with and without different concentrations of DEEQ at $298 \mathrm{~K}$. concentration of corrosion inhibitor is $7 \mathrm{mmol}$, the corrosion inhibition rate can reach over 95\%, which indicates that DEEQ is an effective inhibitor and can meet the requirements of acidification operation of medium and low temperature oil and gas well. ${ }^{15,24}$

\subsection{Potentiodynamic polarization curves}

Fig. 3 shows the potentiodynamic polarization curves for mild steel in $15 \% \mathrm{HCl}$ solution with and without different concentrations of DHAC at $298 \mathrm{~K}$. The electrochemical parameters of the corrosion potential $\left(E_{\text {corr }}\right)$, corrosion current density $\left(i_{\text {corr }}\right)$, anodic Tafel slope $\left(\beta_{\mathrm{a}}\right)$ and cathodic Tafel slope $\left(\beta_{\mathrm{c}}\right)$ obtained by Tafel extrapolation are shown in Table 2 , and the calculation formula of the corrosion inhibition efficiency $(\eta)$ is as follows:

$$
\eta(\%)=\left(1-\frac{i_{\text {corr }}}{i_{\text {corr } 0}}\right) \times 100
$$

where $i_{\text {corr }}$ and $i_{\text {corro }}$ are the corrosion densities with and without inhibitor, respectively. From Table 2, it is clear that with the increase in DEEQ concentration, the corrosion current density of the mild steel electrode in the $15 \% \mathrm{HCl}$ solution decreases, the corrosion efficiency increases, and the corrosion potential shifts negatively. During the linear regions in the anodic and cathodic regions, we can calculate the corrosion parameters, including the corrosion current density, anodic and cathodic Tafel slopes and inhibition efficiency. The corrosion potential on the working electrode in the absence of inhibitor is $-0.4071 \mathrm{~V}$. This value shifts towards the cathodic direction in the presence of DEEQ. The values of $E_{\text {corr }}$ are $-0.4382 \mathrm{~V},-0.4346 \mathrm{~V},-0.43285 \mathrm{~V},-0.4284 \mathrm{~V}$ and $-0.4447 \mathrm{~V}$ in the presence of $1 \mathrm{mM}, 3 \mathrm{mM}, 4 \mathrm{mM}, 6 \mathrm{mM}$ and $7 \mathrm{mM}$, respectively. The values of $i_{\text {corr }}$ are $0.6282 \mathrm{~mA} \mathrm{~cm}^{-2}, 0.3071 \mathrm{~mA} \mathrm{~cm}^{-2}$, $0.2450 \mathrm{~mA} \mathrm{~cm}^{-2}, 0.1708 \mathrm{~mA} \mathrm{~cm}{ }^{-2}, 0.0749 \mathrm{~mA} \mathrm{~cm}^{-2}$ and 0.0491 $\mathrm{mA} \mathrm{cm}{ }^{-2}$ in the absence and presence $1 \mathrm{mM}, 3 \mathrm{mM}, 4 \mathrm{mM}$, $6 \mathrm{mM}$ and $7 \mathrm{mM}$ DEEQ, respectively. The reduction of the current densities and the fact that the displacement in $E_{\text {corr }}$ between the absence and presence of DEEQ is less than $85 \mathrm{mV}$ indicate that DEEQ is a mixed-type inhibitor. ${ }^{\mathbf{8 , 1 2}}$

From Fig. 3, it was found that the addition of DEEQ had no significant effect on the slope of the cathodic polarization curve of the mild steel electrode in the $15 \% \mathrm{HCl}$ solution. The approximately parallel cathodic polarization curve indicates that the inhibitor DEEQ has no impact on the mechanism of the reduction of hydrogen, and the process is under activation control. ${ }^{43,44}$ The addition of DEEQ reduces the number of active

Table 2 The electrochemical parameters for mild steel in $15 \% \mathrm{HCl}$ without and with different concentrations of DEEQ at $298 \mathrm{~K}$

\begin{tabular}{lllrr}
$\begin{array}{l}\text { Concentration } \\
(\mathrm{mM})\end{array}$ & $E_{\text {corr }}\left(\mathrm{V}_{\mathrm{SCE}}\right)$ & $i_{\text {corr }}\left(\mathrm{mA} \mathrm{cm}^{-2}\right)$ & $\beta_{\mathrm{a}}\left(\mathrm{mV} \mathrm{dec}^{-1}\right)$ & $\beta_{\mathrm{c}}\left(\mathrm{mV} \mathrm{dec}^{-1}\right)$ \\
\hline Blank & -0.4071 & 0.6282 & 62.475 & -136.7 \\
1.0 & -0.4382 & 0.3071 & 110.0 & -138.5 \\
3.0 & -0.4346 & 0.2450 & 121.1 & -123.1 \\
4.0 & -0.4285 & 0.1708 & 110.3 & -128.7 \\
6.0 & -0.4284 & 0.0749 & 125.4 & -137.9 \\
7.0 & -0.4447 & 0.0491 & 124.0 & -144.9
\end{tabular}




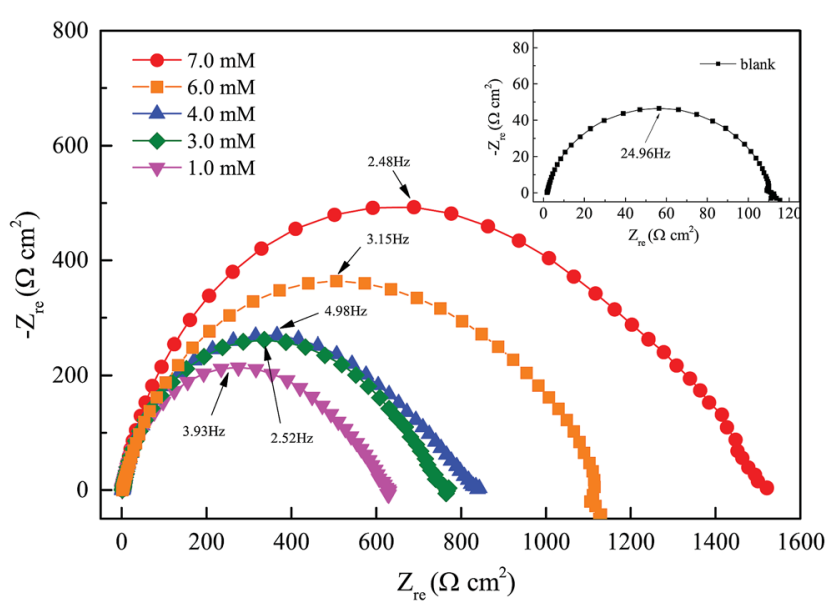

(a)

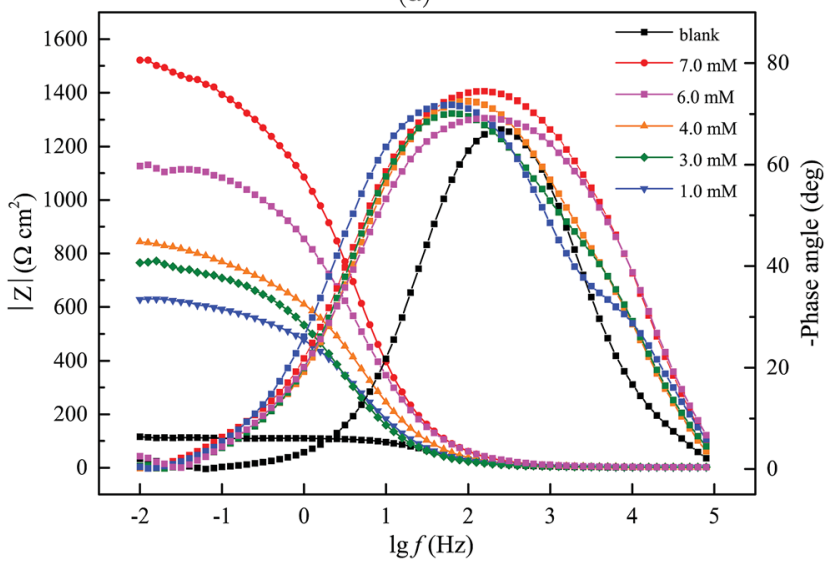

(b)

Fig. 4 EIS for mild steel in a $15 \% \mathrm{HCl}$ solution with and without different concentrations of DEEQ at $298 \mathrm{~K}$ : (a) Nyquist plots and (b) Bode plots.

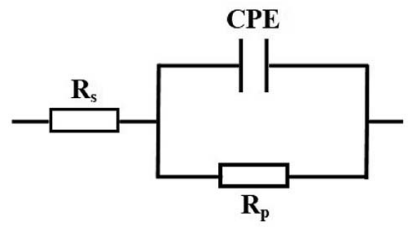

Fig. 5 Equivalent circuit used to fit the obtained impedance spectra for mild steel in a $15 \% \mathrm{HCl}$ solution. sites on the surface of the electrode by adsorption on the mild steel surface, and there was an obvious linear Tafel area on the cathodic polarization curve. It can also be seen from the anodic polarization curve that DEEQ has an evident inhibitory effect on the mild steel electrode at a lower anode potential, which is related to the adsorption of DEEQ on the surface of the mild steel electrode and the formation of a protective layer of inhibitor. ${ }^{10,38}$ However, when the polarization potential continues to increase, it can be observed that the curves are close to coinciding. This may be due to the rapid dissolution of mild steel at the strong polarization potential, which causes the desorption of DEEQ from the electrode's surface.

\subsection{Electrochemical impedance spectroscopy measurements}

Fig. 5 shows the corrosion inhibitory properties of different concentrations of DEEQ in $15 \% \mathrm{HCl}$ solution at $298 \mathrm{~K}$, as tested using electrochemical impedance spectroscopy (EIS). The equivalent circuit model is displayed in Fig. 4 by fitting the impedance data, which contain the solution resistance $\left(R_{\mathrm{S}}\right)$, polarization resistance $\left(R_{\mathrm{p}}\right)$ and constant phase element (CPE), and is given in eqn (6):

$$
Z_{\mathrm{CPE}}=Y_{0}^{-1}(j \omega)^{-n}
$$

where the CPE is the constant phase element to replace a double layer capacitance $C_{\mathrm{dl}}$ to obtain a more accurate fit of the experimental data set. $n$ corresponds to the phase shift, which is related to the inhomogeneities of the double layer. For $n=0$, CPE represents a resistance, for $n=1$, a capacitance and for $n=$ -1 an inductance. The dimension of $Y_{0}$ is $s^{n} \Omega^{-1}$, while that of a capacitance $(C)$ is $\mathrm{s} \Omega^{-1}$ or $\mathrm{F}$. Despite this difference, $Y_{0}$ is often used as if it were the capacitance of the corroding system. Conversion of $Y_{0}$ data into $C$ is very important when experimental capacitance data are to be used to determine quantitatively system parameters. ${ }^{\mathbf{1 4 , 4 0}}$ The "double layer capacitance" values $\left(C_{\mathrm{dl}}\right)$ are calculated as follows:

$$
C_{\mathrm{dl}}=Y_{0}\left(\omega_{m}^{\prime \prime}\right)^{n-1}
$$

where $\omega_{m}^{\prime \prime}$ is the angular frequency corresponding to the maximum imaginary part of the impedance spectrum. The impedance parameters are displayed in Table 3 and the inhibition efficiency $(\eta)$ was calculated by the following equation:

$$
\eta(\%)=\frac{R_{\mathrm{p}}-R_{\mathrm{p}}^{0}}{R_{\mathrm{p}}} \times 100
$$

Table 3 The EIS parameters for mild steel in $15 \% \mathrm{HCl}$ solution without and with different concentrations of DEEQ at $298 \mathrm{~K}$

\begin{tabular}{lllllr}
\hline$C(\mathrm{mM})$ & $R_{\mathrm{S}}\left(\Omega \mathrm{cm}^{2}\right)$ & $R_{\mathrm{p}}\left(\Omega \mathrm{cm}^{2}\right)$ & $Y_{0} \times 10^{4}\left(\Omega^{-1} \mathrm{~s}^{n} \mathrm{~cm}^{-2}\right)$ & $n$ & $C_{\mathrm{dl}}\left(\mu \mathrm{F} \mathrm{cm}{ }^{-2}\right)$ \\
\hline 0 & 1.76 & 109.4 & 2.17 & 0.89 & 114.6 \\
1.0 & 1.31 & 596.9 & 1.85 & 0.80 & 84.6 \\
3.0 & 1.50 & 731.6 & 1.20 & 0.83 & 66.8 \\
4.0 & 1.30 & 772.1 & 1.04 & 0.81 & 49.1 \\
6.0 & 1.38 & 1037 & 0.90 & 0.81 & 41.9 \\
7.0 & 1.25 & 1313 & 0.69 & 0.85 & 38.9
\end{tabular}


where $R_{\mathrm{p}}$ and $R_{\mathrm{p}}^{0}$ are the polarization resistance $\left(\Omega \mathrm{cm}^{2}\right)$ with and without DEEQ, respectively. From Fig. 4(a), it is clear that the Nyquist figure displays a depressed capacitive loop, and with the increase in DEEQ concentration, the radius of the capacitive loop increases, which means that the charge transfer between the solution and mild steel is dramatically hindered by the addition of DEEQ. ${ }^{21,24}$ In addition, the fact that there is no change in the shape of the impedance spectra with the addition of inhibitor indicates that the presence of the inhibitor has no influence on the corrosion mechanism. The Bode and phase angle plots for mild steel in the $15 \% \mathrm{HCl}$ solution with different concentrations of DEEQ are displayed in Fig. 4(b). The phase
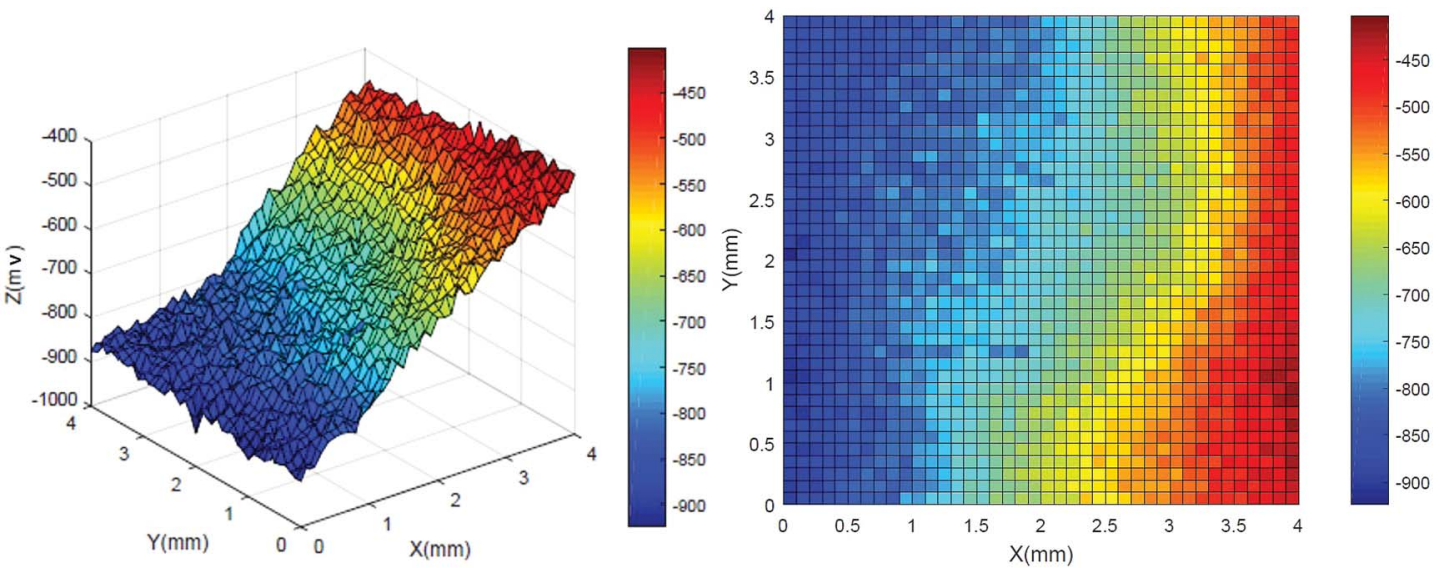

(a)
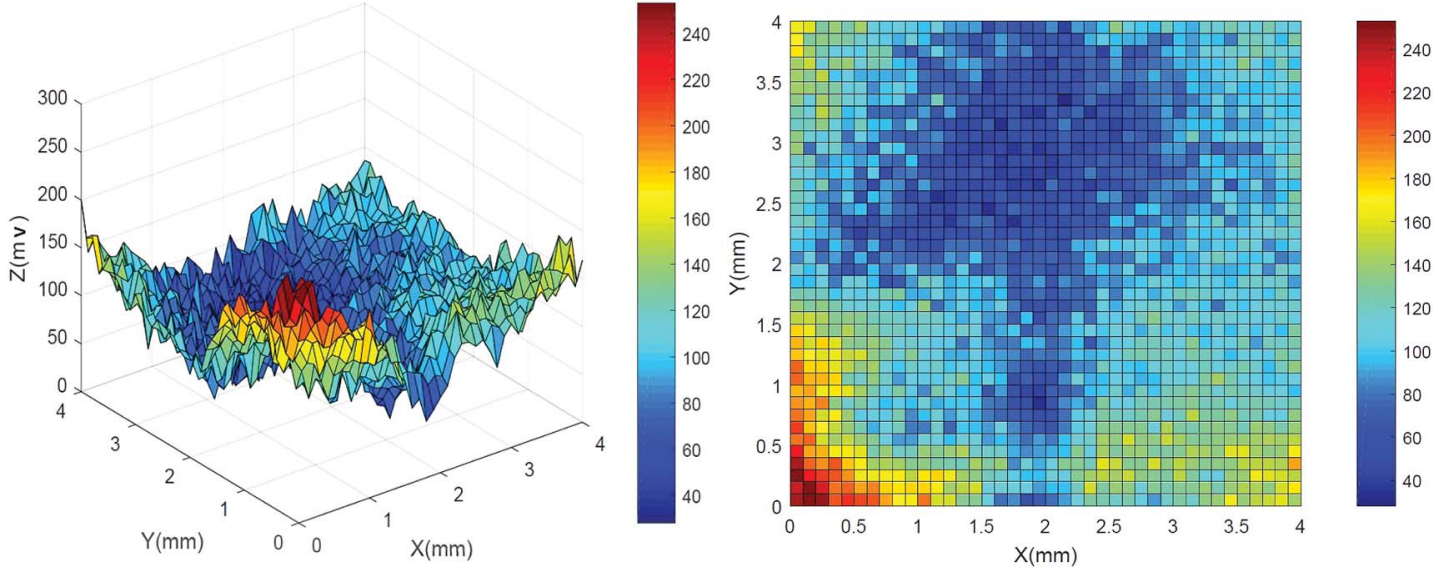

(b)
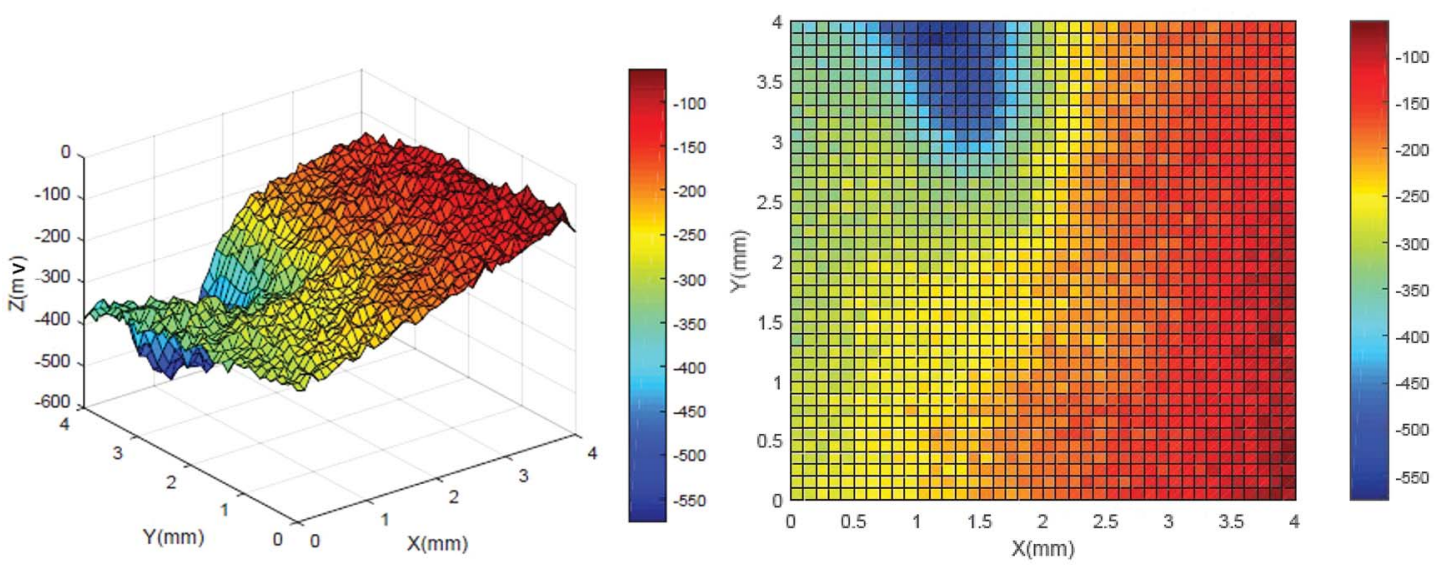

(c)

Fig. 6 Three-dimensional diagrams of the potential distributions for the original state (a), and the absence (b) and presence (c) of DEEQ in 15\% $\mathrm{HCl}$ for $4 \mathrm{~h}$ at $298 \mathrm{~K}$. 
angles of the blank and inhibited solutions are $66^{\circ}$ at $197 \mathrm{~Hz}$, $69^{\circ}$ at $157 \mathrm{~Hz}, 70^{\circ}$ at $60 \mathrm{~Hz}, 71^{\circ}$ at $54 \mathrm{~Hz}, 72^{\circ}$ at $200 \mathrm{~Hz}$ and $74^{\circ}$ at $199 \mathrm{~Hz}$, and with the increase in inhibitor concentration, the absolute impedance gradually increases at low frequencies, which indicates that DEEQ has the higher inhibitory effect. ${ }^{28}$ It can be found from Table 3 that with the increase in the DEEQ concentration, $R_{\mathrm{p}}^{0}$ increases, which indicates that the inhibitor has an evident inhibitory effect after adsorption on the mild steel surface. The minimum polarization resistance $\left(R_{\mathrm{p}}\right)$ of the blank solution is $109.4 \Omega \mathrm{cm}^{2}$, the maximum value of $R_{\mathrm{p}}^{0}$ reaches

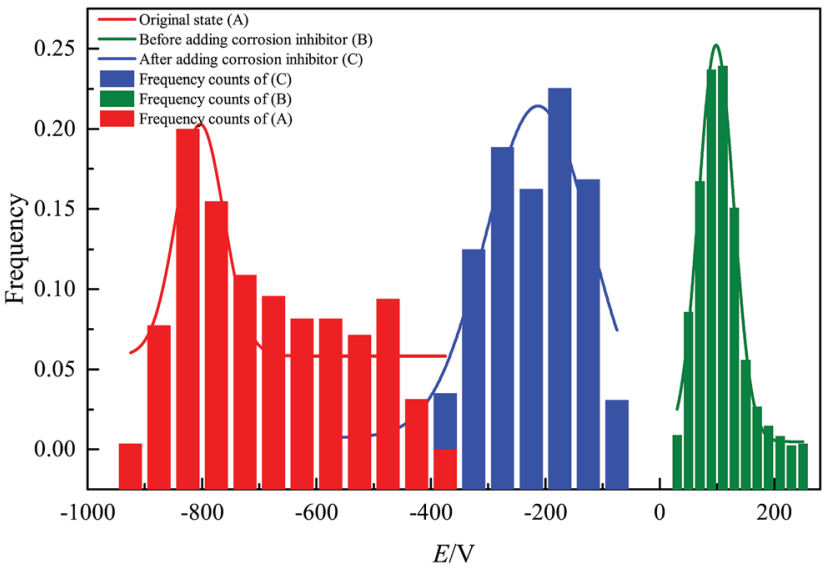

Fig. 7 Histogram of potential distributions and fitting curves of the original state (A), and in the absence (B) and presence (C) of DEEQ.
$1313 \Omega \mathrm{cm}^{2}$ when the concentration is $7.0 \mathrm{mM}$, and $\eta$ is $91.2 \%$. In addition, with the increase in inhibitor concentration the value of the electric double layer capacitance decreases, which is attributed to the inhibitor molecules replacing the water molecules adsorbed on the mild steel surface.

\subsection{Scanning Kelvin probe}

Fig. 6 shows the three-dimensional diagram of potential distribution for the original state (a), and the absence (b) and presence (c) of DEEQ in $15 \% \mathrm{HCl}$ for $4 \mathrm{~h}$ at $298 \mathrm{~K}$. It is clear that the potential distribution of the original state has a negative potential value, and the uneven potential distribution was mainly due to differences in roughness of the specimen surface. Comparing the original state with the result in the absence of DEEQ, the potential distribution of the specimen surface is distinctly positive, which indicates that the surface of the specimen was corroded, causing the potential to move in the positive direction. For the result in the presence of DEEQ (c), the potential distribution was again a negative value, which means that the specimen's surface was effectively protected with the inhibitor, and proves that DEEQ has excellent performance as an inhibitor, corresponding with the inhibitor performance obtained from the weight loss and electrochemical experiments.

Fig. 7 is the GaussAmp fitting curve of the SKP potential distribution on the surface of the specimens in the original state, and in the absence and presence of DEEQ in $15 \% \mathrm{HCl}$ for $4 \mathrm{~h}$ at $298 \mathrm{~K}$, and the fitting formula is shown in the follow equation:
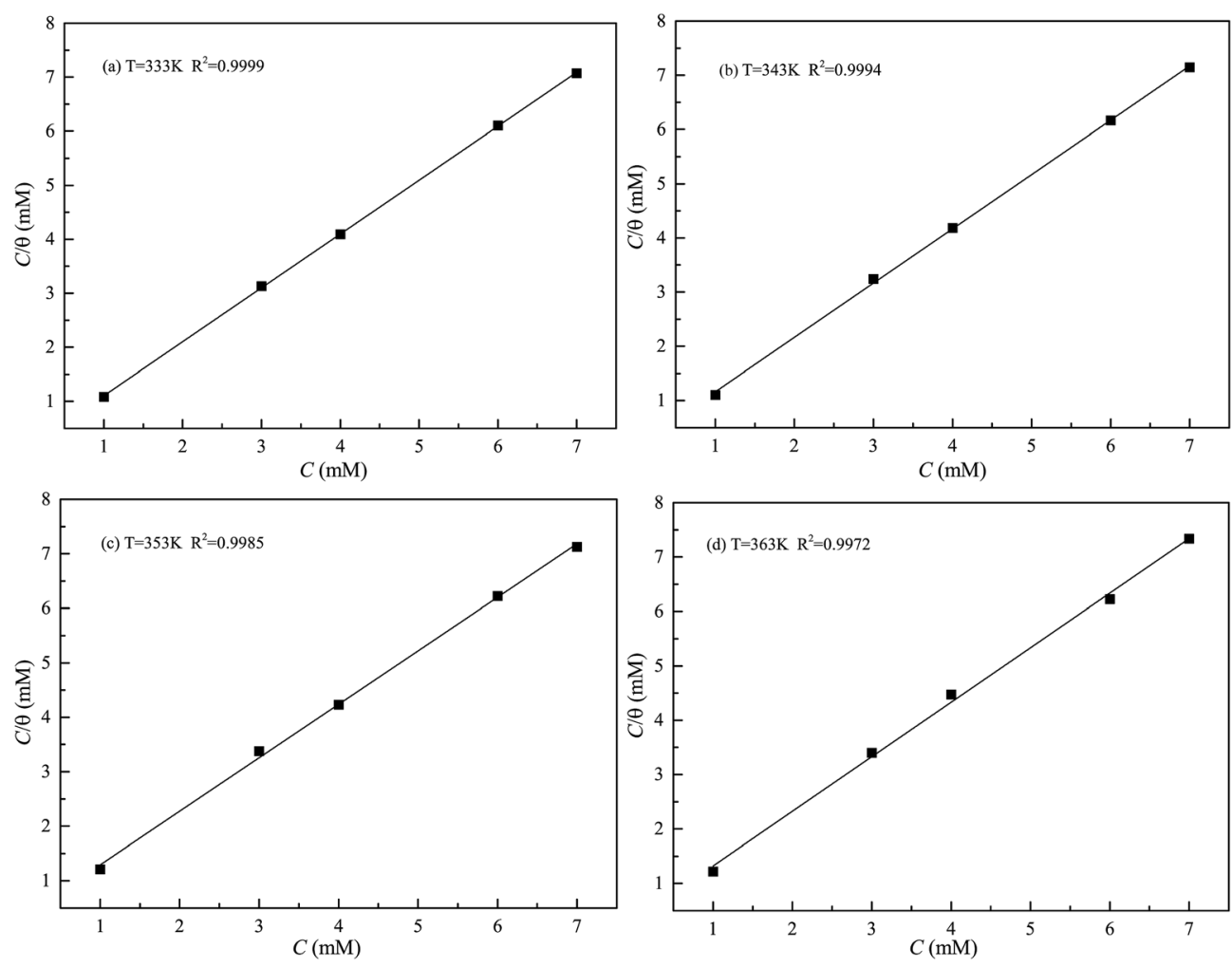

Fig. 8 Langmuir adsorption plots for mild steel in $15 \% \mathrm{HCl}$ solution with different concentrations of DEEQ at different temperatures. 
Table 4 Thermodynamic parameters of adsorption for mild steel in $15 \% \mathrm{HCl}$ solution at different temperatures

\begin{tabular}{lllll}
\hline$T(\mathrm{~K})$ & $K_{\text {ads }}\left(\mathrm{L} \mathrm{mol}^{-1}\right)$ & $\Delta G_{\text {ads }}^{0}\left(\mathrm{~kJ} \mathrm{~mol}^{-1}\right)$ & $\Delta H_{\text {ads }}^{0}\left(\mathrm{~kJ} \mathrm{~mol}^{-1}\right)$ & $\Delta S_{\text {ads }}^{0}\left(\mathrm{~J} \mathrm{~K}^{-1} \mathrm{~mol}^{-1}\right)$ \\
\hline 333 & 9336 & -36.41 & -39.77 \\
343 & 6234 & -36.35 & \\
353 & 3222 & -35.48 & \\
363 & 3128 & -36.39 &
\end{tabular}

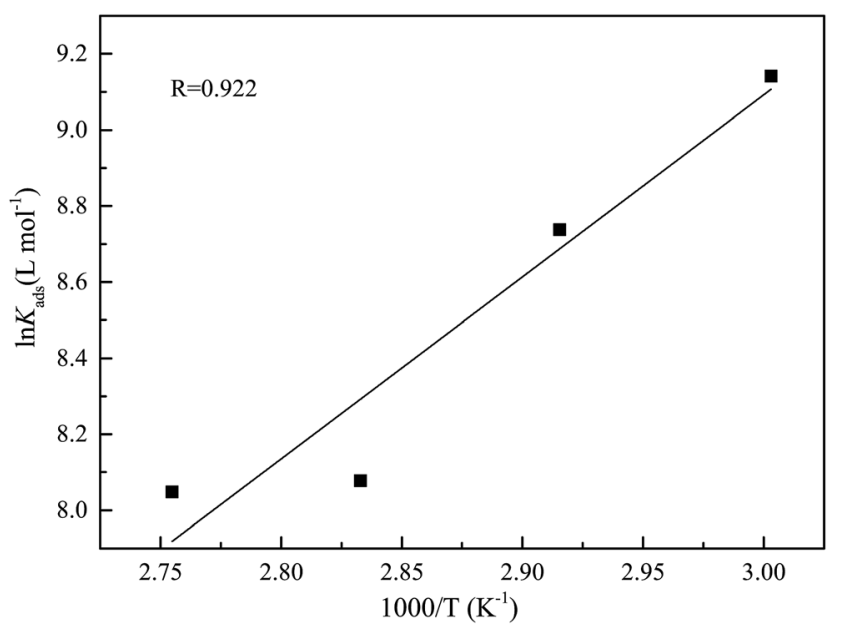

Fig. 9 The relationship between $\ln K_{\text {ads }}$ and $(1000 / T)$ for mild steel in $15 \% \mathrm{HCl}$ solution with different concentrations of DEEQ.

$$
y=y_{0}+A \mathrm{e}^{-\frac{\left(x-x_{\mathrm{c}}\right)^{2}}{2 w^{2}}}
$$

where $A$ is constant, $y_{0}$ is the ordinate offset, $x_{\mathrm{c}}$ is the concentrated position of the potential distribution, $w^{2}$ is the degree of concentration, and the smaller the value, the more concentrated the potential distribution at the $x_{\mathrm{c}}$ value. From the fitting results we find the $x_{\mathrm{c}}$ values of the original state, and in the absence and presence the DEEQ are $-803(\mathrm{mV}), 98(\mathrm{mV})$ and $-213(\mathrm{mV})$, respectively.

\subsection{Adsorption isotherm studies and thermodynamic analysis}

Many literature reports have indicated that organic corrosion inhibitors mainly achieve their inhibitory effects through adsorption on mild steel surfaces, so adsorption isotherm studies can provide more information regarding the interaction between the inhibitor and the mild steel surface. In this part, the classical Langmuir adsorption isotherm was applied to describe the adsorption behavior of DEEQ, and the isotherm can be represented as:

$$
\frac{C}{\theta}=\frac{1}{K_{\mathrm{ads}}}+C
$$

where $K_{\text {ads }}$ is the equilibrium constant of the adsorption process, $C$ is the concentration of inhibitor and $\theta$ is the surface coverage. All of the parameters can be obtained from the weight loss measurement. In addition, the thermodynamic parameters of standard free energy $\left(\Delta G_{\text {ads }}^{0}\right)$, enthalpy $\left(\Delta H_{\text {ads }}^{0}\right)$ and entropy $\left(\Delta S_{\text {ads }}^{0}\right)$ are calculated by the following equations:

$$
\begin{aligned}
K_{\mathrm{ads}} & =\frac{1}{55.5} \exp \left(-\frac{\Delta G_{\mathrm{ads}}^{0}}{R T}\right) \\
\ln K_{\mathrm{ads}} & =\ln \frac{1}{55.5}-\frac{\Delta H_{\mathrm{ads}}^{0}}{R T}+\frac{\Delta S_{\mathrm{ads}}^{0}}{R}
\end{aligned}
$$

where $R$ is the universal gas constant, $T$ is the thermodynamic temperature, and the value of $\mathbf{5 5 . 5}$ is the molar concentration of water in the solution $\left(\mathrm{mol} \mathrm{L}^{-1}\right)$. From Fig. 8 it is clear that there is an obvious linear relationship between $C / \theta$ and $C$, and the value of the regression coefficient $(R)$ is close to 1 at different temperatures, which indicates that the adsorption of DEEQ on the mild steel surface obeys the Langmuir adsorption isotherm. ${ }^{23,26,29}$ Table 4 shows the parameters of adsorption thermodynamics, and it can be found that there is a negative value of $\Delta G_{\text {ads }}^{0}$ at different temperatures, indicating that the adsorption of DEEQ on the surface of mild steel is a spontaneous process. Furthermore, the values of $\Delta G_{\text {ads }}^{0}$ are concentrated around $-33 \mathrm{~kJ} \mathrm{~mol}{ }^{-1}$, which indicates that the

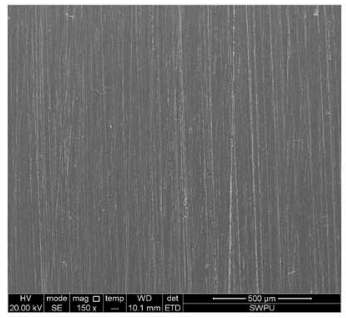

(a)

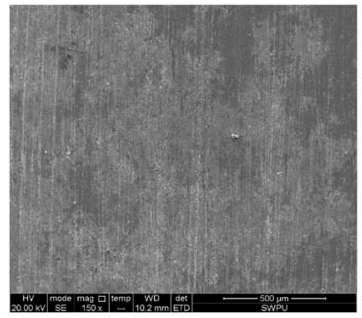

(b)

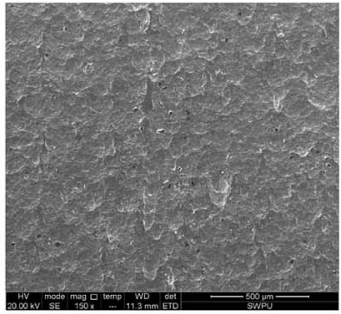

(c)

Fig. 10 SEM micrographs of the mild steel surface before (a) and after immersion in $15 \% \mathrm{HCl}$ solution with (b) and without (c) DEEQ for $4 \mathrm{~h}$ at 298 K. 
Table 5 Element analysis of the mild steel surface before and after immersion in $15 \% \mathrm{HCl}$ solution without DEEQ for $4 \mathrm{~h}$ at $298 \mathrm{~K}$

\begin{tabular}{llllllll}
\hline Element & & $\mathrm{C}$ & $\mathrm{N}$ & $\mathrm{O}$ & $\mathrm{Si}$ & $\mathrm{Mn}$ & $\mathrm{Fe}$ \\
Before & $\mathrm{wt} \%$ & 00.15 & - & 03.99 & 00.67 & 01.72 & 93.47 \\
& at\% & 00.63 & - & 12.53 & 01.20 & 01.57 & 84.06 \\
After & wt $\%$ & 0.11 & 2.41 & 7.39 & 0.61 & 1.87 & 87.60 \\
& at\% & 0.42 & 7.59 & 20.38 & 0.96 & 1.50 & 69.15
\end{tabular}

adsorption of DEEQ on the surface of mild steel is a mixed adsorption, and the results correspond with the data obtained from the electrochemical experiments. In addition, a negative $\Delta H_{\text {ads }}^{0}$ reveals that the adsorption of DEEQ on the metal surface in $15 \% \mathrm{HCl}$ is a exothermic process (Fig. 9). ${ }^{32,33}$

\subsection{Surface analysis}

Fig. 10 shows the SEM micrographs of the fresh specimen (a) and the specimens after immersion in $15 \% \mathrm{HCl}$ solution in the presence (b) and absence (c) of $7.0 \mathrm{mM}$ DEEQ for $4 \mathrm{~h}$ at $363 \mathrm{~K}$. It can be seen from the images that the surface of the specimen is seriously damaged in the absence of inhibitor due to the corrosive acid solution, ${ }^{22,23}$ and the specimen shows a smooth surface in the presence of inhibitor. In addition, elemental analysis was carried out by using energy dispersive spectroscopy (EDS), and the results are shown in Table 5. Comparing the samples in the absence and presence inhibitor, the content of the element $\mathrm{N}$ increased significantly, indicating that an adsorption film was formed on the surface of the specimen, ${ }^{\mathbf{1 6}-18}$ which isolated the acid solution and protected the specimen. These results are consistent with the inhibitor performance results obtained from the weight loss, SKP, adsorption isotherm and electrochemical experiments.

\subsection{Quantum chemical calculations}

In order to further understand the corrosion inhibition mechanism of DEEQ, quantum chemical calculations were performed. The optimized geometry structure of DHAC and the electron density distributions of the HOMO and LUMO are displayed in Fig. 11 and Table 6 shows the associated quantization parameters such as $E_{\text {Hомо }}, E_{\text {LUMO }}, \Delta E$ and the dipole moment $\mu$. It can be seen that the electron density distributions of both the HOMO and LUMO are evenly distributed on the
Table 6 Quantum chemical parameters for the DEEQ cation

\begin{tabular}{llll}
\hline HOMO $(\mathrm{eV})$ & LUMO $(\mathrm{eV})$ & $\Delta E(\mathrm{eV})$ & $\mu(\mathrm{D})$ \\
\hline-8.43009172 & -6.052359588 & 2.377732132 & 10.748355 \\
\hline
\end{tabular}

benzene ring, indicating the benzene ring is the active site of adsorption. ${ }^{39}$ On the other hand, because of the plane conjugated structure, the inhibitor DEEQ is considered to adsorbed smoothly on the surface of the mild steel.

According to frontier molecular orbital theory, the reactivity of the molecule is closely related to the highest occupied molecular orbital (HOMO) and the lowest unoccupied molecular orbital (LUMO). ${ }^{18}$ The HOMO and LUMO orbits are related to the ability of the molecule to give and accept electrons, respectively. A high $E_{\text {Hомо value means that the molecule has }}$ a strong electron donating ability, and the lower the $E_{\text {LUMO }}$ value the easier the molecule accepts electrons. Therefore, when the corrosion inhibitor molecules have a high $E_{\text {HOMO }}$ and low $E_{\text {LUMO }}$, the electron transfer between the inhibitor molecules and the metal surface is easy, and the inhibitor shows high corrosion inhibition performance. ${ }^{45}$ From Table 6 , both the $E_{\text {HOMO }}$ and $E_{\text {LUMo }}$ values are lower, which means that the DEEQ cation accepts electrons more easily than it donates electrons. Compared with the tiny $\mu$ value of $\mathrm{H}_{2} \mathrm{O}$, the DEEQ cation is more likely to replace the water molecules adsorbed on the surface of mild steel.

Table 7 shows the Mulliken charges of the atoms in the DEEQ cation. It was found that the charges of C2, C9, C11, C22, C24 and C26 are positive, while the charges of the benzene ring are negative, and the net charge of all the atoms of DEEQ is negative. Therefore, the conjugated benzene ring can offer electrons to form a coordinate bond with the metal orbital. In addition, the site of the positive charge can accept electrons to interact with the metal surface by electrostatic attraction, which all indicates that DEEQ can easily adsorb on the metal's surface.

\subsection{Molecular dynamic simulations}

In order to research the microscopic behavior of the inhibitor adsorbed on the mild steel Fe (100) surface, the equilibrium configuration for DEEQ in an aqueous system was simulated, and the result is shown in Fig. 12. It can be seen that the DEEQ

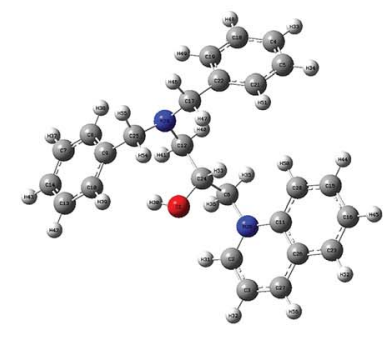

(a)

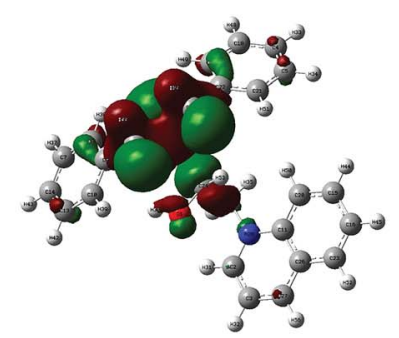

(b)

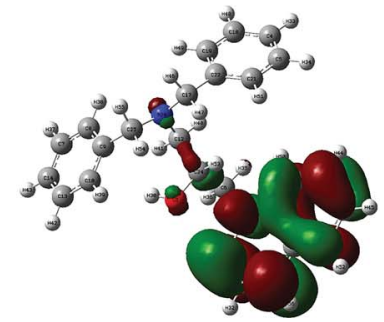

(c)

Fig. 11 Optimized geometric structure (a) and the electron density distributions of the HOMO (b) and LUMO (c) for the DEEQ cation. 
Table 7 The Mulliken charge of atoms in the DEEQ cation

\begin{tabular}{|c|c|c|c|c|c|c|c|c|c|}
\hline Atom & N1 & N2 & $\mathrm{O} 1$ & $\mathrm{C} 2$ & C3 & $\mathrm{C} 4$ & C5 & C6 & C7 \\
\hline Mulliken charge & -0.4845 & -0.3892 & -0.6470 & 0.1391 & -0.1806 & -0.1271 & -0.1345 & -0.2145 & -0.1296 \\
\hline C8 & C9 & C10 & C11 & C12 & C13 & C14 & C15 & C16 & C17 \\
\hline-0.1634 & 0.1091 & -0.2291 & 0.3403 & -0.1871 & -0.1273 & -0.1275 & -0.1304 & -0.1132 & -0.2030 \\
\hline-0.1297 & -0.1650 & -0.1567 & -0.2037 & 0.1272 & -0.1836 & 0.1337 & -0.2036 & 0.1190 & -0.0982 \\
\hline
\end{tabular}
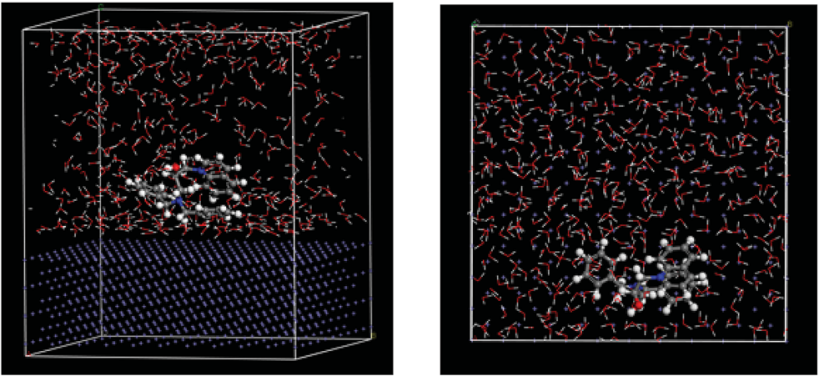

Fig. 12 Equilibrium configuration of DEEQ in an aqueous system (side view and top view)

cation is parallel with the Fe (100) surface, which indicates that the planar structure of the dibenzylamine ring is the dominant factor for the adsorption orientation. In an aqueous system, the DEEQ molecules have a strong mutual attraction between the active sites and the Fe (100) surface, causing the inhibitor molecules to be immobilized on the metal surface. The kinetic simulation results show that the adsorption energy of the molecule is $-2174.93 \mathrm{~kJ} \mathrm{~mol}^{-1}$, which is much larger than that of the water molecules on the $\mathrm{Fe}$ (100) surface of $-24.64 \mathrm{~kJ} \mathrm{~mol}^{-1},{ }^{24}$ indicating that the inhibitor molecules can expel the water molecules and adsorbed on the Fe (100) surface. It can be inferred that the inhibitor molecules can aggregate and adsorb on the metal surface to form a dense molecular film layer in the liquid phase corrosive medium, separating the metal surface from the water molecules and the corrosive medium to achieve the effect of corrosion inhibition.

\section{Conclusion}

Weight loss and SEM measurements revealed that DEEQ is an effective inhibitor through adsorption on the mild steel surface, blocking contact between the acidic medium and metal surface, and the inhibitor exhibited a 95.4\% maximum inhibition efficiency at $363 \mathrm{~K}$, which can meet the requirements of acidification operation of medium and low temperature oil and gas well. The contact angle experiment shows that the corrosion inhibitor can change the wettability of the steel sheet surface, thus inhibiting acid corrosion of oil and gas string. Electrochemical experiments showed that DEEQ can inhibit both the anodic and cathodic corrosion processes, and indicated that DEEQ is a mixed inhibitor. From the microscopic point of view, scanning Kelvin probe (SKP) experiments further proved that DEEQ has an obvious inhibitory effect, and the adsorption of DEEQ on mild steel obeys the Langmuir adsorption isotherm. Theoretical calculations revealed that the DEEQ molecules can provide electrons to the metal atomic orbital with a strong interaction. The results further demonstrated that DEEQ has an evident inhibitory effect for oil and gas field acidification.

\section{Conflicts of interest}

There are no conflicts to declare.

\section{Acknowledgements}

This work was supported by the Sichuan Youth Science and Technology Innovation Research Team Program (2017TD0013) and the Major Program of the National Natural Science Foundation of China (Grant No. 51490653).

\section{References}

1 A. Alagta, I. Felhösi, I. Bertoti, et al., Corrosion protection properties of hydroxamic acid self-assembled monolayer on carbon steel, Corros. Sci., 2008, 50(6), 0-1649.

2 M. T. Alhaffar, S. A. Umoren, I. B. Obot, et al., Isoxazolidine derivatives as corrosion inhibitors for low carbon steel in $\mathrm{HCl}$ solution: experimental, theoretical and effect of $\mathrm{KI}$ studies, RSC Adv., 2018, 8(4), 1764-1777.

$3 \mathrm{~J}$. Aljourani, K. Raeissi and M. A. Golozar, Benzimidazole and its derivatives as corrosion inhibitors for mild steel in $1 \mathrm{M}$ HCl solution, Corros. Sci., 2009, 51(8), 0-1843.

4 P. Arellanes-Lozada, O. Olivares-Xometl, N. V. Likhanova, et al., Adsorption and performance of ammonium-based ionic liquids as corrosion inhibitors of steel, J. Mol. Liq., 2018, 151-163.

5 F. Bentiss, C. Jama, B. Mernari, et al., Corrosion control of mild steel using 3,5-bis(4-methoxyphenyl)-4-amino-1,2,4triazole in normal hydrochloric acid medium, Corros. Sci., 2009, 51(8), 0-1635.

6 D. Daoud, T. Douadi, H. Hamani, et al., Corrosion inhibition of mild steel by two new S-heterocyclic compounds in $1 \mathrm{M}$ $\mathrm{HCl}$ : Experimental and computational study, Corros. Sci., 2015, 94, 21-37.

7 Q. Deng, N. N. Ding, X. L. Wei, L. Cai, X. P. He and Y. T. Long, Identification of diverse 1,2,3-triazole-connected benzyl glycoside-serine/threonine conjugates as potent corrosion inhibitors for mild steel in $\mathrm{HCl}$, Corros. Sci., 2012, 64(6), 64-73.

8 A. A. Farag, A. S. Ismail and M. A. Migahed, Environmentalfriendly shrimp waste protein corrosion inhibitor for carbon steel in $1 \mathrm{M} \mathrm{HCl}$ solution, Egypt. J. Pet., 2018, 1187-1194. 
9 H. X. Feng, J. Li and X. H. Gao, Electrochemical Studies of some New Mannich Bases Compounds as Corrosion Inhibitors for Mild Steel in Acidic Media, Adv. Mater. Res., 2012, 538-541, 2329-2333.

10 A. S. Fouda, M. A. Ismail, A. S. Abousalem, et al., Experimental and theoretical studies on corrosion inhibition of 4-amidinophenyl-2,2'-bifuran and its analogues in acidic media, $R S C A d v ., 2017,7(73), 46414-$ 46430.

11 H. J. Habeeb, H. M. Luaibi, R. M. Dakhil, et al., Development of new corrosion inhibitor tested on mild steel supported by electrochemical study, Results Phys., 2018, 1260-1267.

12 H. Hamani, T. Douadi, D. Daoud, et al., 1-(4-Nitrophenyloimino)-1-(phenylhydrazono)-propan-2-one as corrosion inhibitor for mild steel in $1 \mathrm{M} \mathrm{HCl}$ solution: Weight loss, electrochemical, thermodynamic and quantum chemical studies, J. Electroanal. Chem., 2017, 801, 425-438.

13 K. Haruna, I. B. Obot, N. K. Ankah, et al., Gelatin: A green corrosion inhibitor for carbon steel in oil well acidizing environment, J. Mol. Liq., 2018, 264, 515-525.

14 F. Mansfeld and C. H. Hsu, Concerning the conversion of the constant phase element parameter $y_{0}$ into a capacitance, Corrosion, 2001, 57, 747-748.

$15 \mathrm{Z}$. Hu, Y. Meng, X. Ma, et al., Experimental and theoretical studies of benzothiazole derivatives as corrosion inhibitors for carbon steel in $1 \mathrm{M} \mathrm{HCl}$, Corros. Sci., 2016, 112, 563-575.

16 E. B. Ituen, O. Akaranta and S. A. Umoren, N-Acetyl cysteine based corrosion inhibitor formulations for steel protection in 15\% HCl solution, J. Mol. Liq., 2017, 112-118.

$17 \mathrm{~S}$. John and A. Joseph, Electro analytical, surface morphological and theoretical studies on the corrosion inhibition behavior of different 1,2,4-triazole precursors on mild steel in $1 \mathrm{M}$ hydrochloric acid, Mater. Chem. Phys., 2012, 133(2-3), 1083-1091.

18 O. Kaczerewska, R. Leiva-Garcia, R. Akid, et al., Efficiency of cationic Gemini surfactants with 3azamethylpentamethylene spacer as corrosion inhibitors for stainless steel in hydrochloric acid, J. Mol. Liq., 2017, 247, 6-13.

19 L. Guo, S. Zhu, S. Zhang, et al., Theoretical studies of three triazole derivatives as corrosion inhibitors for mild steel in acidic medium, Corros. Sci., 2014, 87, 366-375.

20 S. Masroor, M. Mobin, M. J. Alam, et al., The novel iminium surfactant p-benzylidene benzyldodecyl iminium chloride as a corrosion inhibitor for plain carbon steel in $1 \mathrm{M} \mathrm{HCl}$ : electrochemical and DFT evaluation, $R S C A d v ., 2017,7(37)$, 23182-23196.

21 P. Mayakrishnan, S. H. Kim, H. Venkatesan, et al., Rhus verniciflua as a green corrosion inhibitor for mild steel in $1 \mathrm{M} \mathrm{H}_{2} \mathrm{SO}_{4}, R S C A d v ., 2016,6(62), 2046-2069$.

22 N. A. Negm, A. M. A. Sabagh, M. A. Migahed, et al., Effectiveness of some diquaternary ammonium surfactants as corrosion inhibitors for carbon steel in $0.5 \mathrm{M} \mathrm{HCl}$ solution, Corros. Sci., 2010, 52(6), 0-2132.

23 A. Popova, M. Christov, A. Vasilev, et al., Mono- and dicationic benzothiazolic quaternary ammonium bromides as mild steel corrosion inhibitors. Part I: Gravimetric and voltammetric results, Corros. Sci., 2011, 53(2), 0-686.

24 Q. Ma, S. Qi, X. He, et al., 1,2,3-Triazole derivatives as corrosion inhibitors for mild steel in acidic medium: Experimental and computational chemistry studies, Corros. Sci., 2017, 129, 91-101.

25 Y. Qiang, S. Zhang, B. Tan, et al., Evaluation of Ginkgo leaf extract as an eco-friendly corrosion inhibitor of X70 steel in HCl solution, Corros. Sci., 2018, 6-16.

26 Z. Salarvand, M. Amirnasr, M. Talebian, et al., Enhanced corrosion resistance of mild steel in $1 \mathrm{M} \mathrm{HCl}$ solution by trace amount of 2-phenyl-benzothiazole derivatives: Experimental, quantum chemical calculations and molecular dynamics (MD) simulation studies, Corros. Sci., 2017, 114, 133-145.

27 T. A. Salman, K. F. Al-Azawi, M. I. Mahdi, et al., Experimental studies on inhibition of mild steel corrosion by novel synthesized inhibitor complemented with quantum chemical calculations, Results Phys., 2018, 10, 291-296.

28 S. M. Shaban, N-(3-(Dimethyl benzyl ammonio) propyl) alkanamide chloride derivatives as corrosion inhibitors for mild steel in $1 \mathrm{M} \mathrm{HCl}$ solution: experimental and theoretical investigation, $R S C A d v ., 2016$, 6(46), 3978439800 .

29 A. K. Singh and M. A. Quraishi, The effect of some bisthiadiazole derivatives on the corrosion of mild steel in hydrochloric acid, Corros. Sci., 2010, 52(4), 0-1385.

30 A. K. Singh and M. A. Quraishi, Investigation of the effect of disulfiram on corrosion of mild steel in hydrochloric acid solution, Corros. Sci., 2011, 53(4), 0-1297.

31 V. V. Torres, R. S. Amado, C. Faia de Sá, et al., Inhibitory action of aqueous coffee ground extracts on the corrosion of carbon steel in $\mathrm{HCl}$ solution, Corros. Sci., 2011, 53(7), 02392.

$32 \mathrm{X}$. Wang, H. Yang and F. Wang, An investigation of benzimidazole derivative as corrosion inhibitor for mild steel in different concentration $\mathrm{HCl}$ solutions, Corros. Sci., 2011, 53(1), 0-121.

33 X. Wang, H. Yang and F. Wang, A cationic Gemini-surfactant as effective inhibitor for mild steel in $\mathrm{HCl}$ solutions, Corros. Sci., 2010, 52(4), 0-1276.

34 W. Wu, M. Chen, S. Liang, et al., Superhydrophobic surface from $\mathrm{Cu}-\mathrm{Zn}$ alloy by one step $\mathrm{O}_{2}$ concentration dependent etching, J. Colloid Interface Sci., 2008, 326(2), 478-482.

35 K. Xhanari, M. Finšgar, M. Knez Hrnčič, et al., Green corrosion inhibitors for aluminium and its alloys: a review, RSC Adv., 2017, 7(44), 27299-27330.

36 Y. Xiu-Fang, T. Min-Min and M. A. Yang-Min, Mannich Base as Corrosion Inhibitor for N80 Steel in HCl Solution, Surf. Technol., 2017, 175-181.

37 J.-Q. Xue, X.-N. Ma, L.-H. Yu, C.-B. Tang and J. Ma, Development of a novel acidification corrosion inhibitor for P110 steel at high temperature, Sci. Adv. Mater., 2012, 4(1), 61-67.

38 X. Yang, F. Li and W. Zhang, 4-(Pyridin-4-yl) thiazol-2-amine as an efficient non-toxic inhibitor for mild steel in 
hydrochloric acid solutions, RSC Adv., 2019, 9(19), 1045410464.

39 N. Yilmaz, A. Fitoz, y. Ergun, et al., A Combined Electrochemical and Theoretical Study into the Effect of 2((thiazole-2-ylimino) methyl) phenol as a Corrosion Inhibitor for Mild Steel in a Highly Acidic Environment, Corros. Sci., 2016, 110-120.

40 R. Yıldiz, An electrochemical and theoretical evaluation of 4,6-diamino-2-pyrimidinethiol as a corrosion inhibitor for mild steel in HCl solutions, Corros. Sci., 2014, 90, 544-553.

41 Y. Pan, F. Zhan, Z. Lu and Y. Lin, A Mannich base 1-phenyl-3(1-pyrrolidinyl)-1-propanone: synthesis and performance study on corrosion inhibition for N80 steel in 15\% hydrochloric acid, Anti-Corros. Methods Mater., 2016, 63(2), 153-159.
42 D. Zhang, Y. Tang, S. Qi, et al., The inhibition performance of long-chain alkyl-substituted benzimidazole derivatives for corrosion of mild steel in $\mathrm{HCl}$, Corros. Sci., 2015, 102, 517-522.

43 X. Zheng, S. Zhang, W. Li, L. Yin, J. He and J. Wu, Investigation of 1-butyl-3-methyl-1H-benzimidazolium iodide as inhibitor for mild steel in sulfuric acid solution, Corros. Sci., 2014, 80(3), 383-392.

44 X. Zheng, S. Zhang, W. Li, M. Gong and L. Yin, Experimental and theoretical studies of two imidazolium-based ionic liquids as inhibitors for mild steel in sulfuric acid solution, Corros. Sci., 2015, 95, 168-179.

45 L. Zhou, Y. L. Lv, Y. X. Hu, et al., Experimental and theoretical investigations of 1,3,5-tris(4-aminophenoxy) benzene as an effective corrosion inhibitor for mild steel in 1, M HCl, J. Mol. Liq., 2018, 249, 179-187. 